\title{
Eesti kultuuri suurpeod maailmapärandis ${ }^{1}$
}

Iivi Zajedova

Teesid: Tänapäeval on eestlaste omakultuuri suurpidude traditsioon rikkalik teema, mida võib pidada eesti rahvale sügavalt omaseks. Samas on see ka unikaalne võimalus hoida ja edasi viia rahvuslikku pärandit mitmekesise harrastustegevusega. Käesolev teemanumber kasvas välja 2012. aastal alustatud uuringust, mis püüdis välja selgitada rahvatantsuharrastuse ja suurpidude traditsiooni rolli omakultuuri hoidmisel. Ajakirjanumbri koostamise ajendiks sai küsimus eesti harrastustegevuse ja suurpidude rollist üha muutuvas maailmas - nende jätkusuutlikkusest ning rahvusliku identiteedi traditsioonide edasikandmisest. Numbrisse on koondatud erinevate riikide ülikooli õppejõudude ja teadurite artiklid, mis käsitlevad suurpidudega seotud harrastustegevuse kogemusi ja kultuuripanust nii Eestis kui ka väljaspool seda.

Märksõnad: harrastustegevus, rahvatants, suurpeod, traditsioon

Uuringu "Rahvatantsuharrastuse ja rahvatantsijate suurürituste roll omakultuuri hoidmisel" viimases faasis korraldati 14. septembril 2015 Tallinna Ülikoolis rahvusvaheline konverents "Eesti kultuuri suurpeod maailmapärandis”. ${ }^{2}$ Selle lõpus tekkis arutluse käigus idee koostada harrastustegevuse ja suurpidude teemanumber, mille üks eesmärk on tekitada ühiskonnas laiemat arutelu harrastustegevuse ja suurpidude rolli üle üha muutuvas maailmas. Käesoleva numbri kuue autori ${ }^{3}$ artiklid käsitlevadki konverentsil esitatud kultuuripärandi hoidmise ja rolliga seotud teemasid.

Guntis Šmidchens Seattle’i Washingtoni Ülikoolist mõtiskleb Baltimaade laulupidude koha üle maailma vaimses kultuuripärandis ning vaatleb uute ja traditsiooniliste laulude suhet laulupidudel. ${ }^{4}$ Sille Kapper Tallinna Ülikoolist analüüsib kahte tantsumaailma - pärimuslik tantsimine ja rahvatantsuharrastus -, küsides, missugune on tantsupidudel osalemise, pärimusliku tantsimisega seotud teadmiste ja oskuste säilitamise ning edasikandmise roll nüüdisaja Eestis ning missugust omakultuuri hoiame tantsupidudel. Petri Hoppu Tampere 
Ülikoolist käsitleb põhjanaabrite koltasaamide rahvatantsu osa nende ajaloo, identiteedi ja tuleviku määratlemisel ning tänapäeva koltasaamide rahvatantsu ja identiteedi seoseid. Triinu Ojamaa Eesti Kirjandusmuuseumist kirjeldab Teise maailmasõja pagulaste kultuurisündmuste jäädvustamist kitsasfilmil Rootsis ning filmitud isikute, paiga ja aja tuvastamist ekspertgrupi poolt. Indiana Ülikooli emeriitprofessor Ain Haas käsitleb vanade rahvapillide traditsioonide taaselustumist nii Eestis kui ka väliseestlaste seas, nähes seda kui vastupanu ilmingut moodsa ühiskonna homogeensusele ning linnastumisele. Kieli ülikooli emeriitprofessor Hain Rebas arutleb võorrvõimu mõjude üle, keskendudes rahva vägivaldse lahutamise tulemusel tekkinud lõhestatusele koorimuusikas.

Alljärgnevalt tutvustan lähemalt konverentsile eelnenud uuringut ja selle tulemusi. Põhiliselt toetuti aastatel 2012-2015 välitöödel kogutud materjalile (intervjuud, küsitlused, osalusvaatlused, märkmed jms) rahvatantsuga tegelevate eestlaste hulgas ning kasutati Eestis ja väljaspool Eestit asuvate seltside väljaandeid. ${ }^{5}$

\section{Rahvatantsuharrastusest ja suurpidudest üldiselt}

Võrreldes teiste pärimuskultuuriliikidega on Eestis rahvatantsu suurüritusi ja sellega seotud traditsioone uuritud suhteliselt vähe. Erilist tähelepanu pole pööratud ka rahvatantsijate ja suurpidude rollile omakultuuri hoidmisel.

21. sajandi esimesel kümnendil on Eestis tantsupeole registreeruvate rühmade hulk võrreldes varasemate aastatega plahvatuslikult kasvanud. Seoses rahvatantsuga on tekkinud mitmeid uusi ideid ja huvitavaid lähenemisi, nagu näiteks meeste tantsupidu, naiste tantsupidu, projekt "Kaerajaan Euroopasse", teatetantsumaraton, talvine tuhamägede tantsupidu jne. Sotsioloogiliste uuringute põhjal võib väita, et rahvatantsu harrastajaskond on ühiskonnas lai ja vähemalt kolmveerand Eesti elanikkonnast on tantsupidu näinud. ${ }^{6}$ See kinnitab rahvatantsu arvestatavat positsiooni ühiskonnas.

Kuigi Eestis on peetud suuri tantsupidusid, mis on koos laulupidudega hinnatud ja kantud UNESCO vaimse kultuuripärandi nimistusse, ${ }^{7}$ on see samas võrdlemisi uus kultuurinähtus, mille esimesed sammud tehti 20. sajandi esimestel kümnenditel. Mälestused tantsupidude tunnustatud juhtidest (Anna Raudkats, Ernst Idla ja Ullo Toomi) sisaldavad suurel määral teavet tantsupidude traditsiooni alguse kohta, kirjeldades tantsupidude traditsiooni kujunemise etappe ja olulisust oma ajas (Kermik 1983; Tõnnus 1991; Idla \& Normet \& Tiik 1991). Rahvatantsupidu võib iseloomustada kui rahvatantsijate massettekannet, mille oluline väljendus avaldub kujundtantsimise vaatemängus. Kristin Kuutma kirjeldab tantsupidu kui massitegevust, pidades massilisust üheks 
tantsupeo oluliseks komponendiks. Ühistegevus võimaldab kõigil harrastada rahvatantsu ja saada osa sellega kaasnevast seltsielust. ${ }^{8}$ Rahvatantsu suurpidusid võib vaadelda ka kui pidevat protsessi, kusjuures suurpidude ettevalmistuse käigus on olulised nii lavastajate ja tantsujuhtide koolitamine kui ka tantsijate arendamine. 20. sajandi teisel kümnendil, mil noorsoo-organisatsioonid korraldasid ohtralt omakultuuri edendavaid kontserte, tekkis vajadus uudse repertuaari järele. Teisalt sai aga vanade rahvatantsude taandumine üheks rahvatantsude kogumise põhjuseks (Raudkats 2001: 9 [1926]).

Juba 1915. aastal esitati rahvatantse Tartu Vanemuises esimest korda lavastusena (Talve 2004: 583). ${ }^{9}$ Suureks toeks sai rahvatantsuharrastusele aga 1919. aastal asutatud Ülemaailmne Eesti Noorsoo Ühendus (ÜENÜ), mille liikmed viljelesid ja tutvustasid rahvakombeid, -tantse ja -mänge (Arraste jt 2009: 9). Suureks tantsupeoks võib pidada 1926. aastal toimunud esimest eesti omakultuuri õhtut (Aassalu 1999: 3-4; Arraste 2009: 23). Esimeseks üldtantsupeoks loetakse aga kokkuleppeliselt 1934. aastal I Eesti mängude raames toimunud võimlejate, rahvatantsijate ja pillimängijate ühisetendust, mida peetakse tänaste üleriigiliste tantsupidude eelkäijaks. ${ }^{10}$ Esimestele mängudele järgnesid (ühtlasi ka viimased) II Eesti mängud 1939. aastal, andes tugeva tõuke rahvatantsu kui kultuuri- ning vaba aja tegevuse arengule nii Eesti esimese iseseisvusperioodi ajal kui ka hiljem ja seda nii Eestis kui ka väljaspool Eestit asuvates eestlaste kogukondades (vt nt Nemeržitski \& Zajedova 2015b: 57-58).

Teise maailmasõja järel toimus eesti rahvakultuuris sunniviisiline jagunemine (vt Kool 1999; Jürgenson 2012: 9; Vasilas 2014), mil paljud Eesti Vabariigi kodanikud põgenesid Nõukogude okupatsiooni eest vabasse maailma, killunedes geograafiliselt väliseestlasteks ja kodueestlasteks, kes jäid üksteisest eraldatuks kuni taasiseseisvumiseni 1991. aastal (Arraste \& Zajedova \& Rüütel 2011). Lahutatud eesti kogukonnad püüdsid üksteisest sõltumatult hoida oma traditsioone, aga et erinevad olid nii olud kui ka tingimused, kulges ka kultuuri areng erinevalt. Siiski on vaatamata võõrvõimu poolt tekitatud vägivaldsele ja valulikule eraldatusele jätkatud tänapäevani omakultuuri suurpidude traditsiooni (Zajedova 2013a; 2013b; 2015).

\section{Traditsioon, kultuur, rahvatants}

Mitmetahulist mõistet traditsioon käsitleti uuringus laiemas mõttes traditsioonina põlvest põlve edasiantud kultuuriilminguna (ÕS 1999: 817; vt ka http:// www.folkloorinoukogu.ee/Moisted_198.htm). Erinevatest uurimustest võib leida termini kultuur kohta rohkesti kvalitatiivselt eristuvaid definitsioone, millele võib anda mitmesuguse sisu. Teemast lähtudes vaadeldi kõnealuses 
uurimuses kultuuri kui elulaadi, mis tugineb mingisugusele ühiste tähenduste süsteemile ning mida antakse sellessamas süsteemis põlvest põlve edasi (Danesi \& Perron 2005: 31; Hofstede 2001: 10). Ka rahvatantsu mõiste defineerimine on viimasel paarikümnel aastal olnud problemaatiline (Hoppu 2004: 101; Kapper 2012; Kapper 2013b). ${ }^{11}$ Seda mitte ainult tantsukultuuris eneses asetleidnud muutuste tõttu, vaid rohkem seoses mõtteviisi ja elulaadi muutusega (Kapper 2015: 27-50). Nõustudes rahvatantsu eristusviisidega, milleks on traditsiooniliste käitumismudelitega seotud tants (Cohen-Stratyner 2001: 121), rahvatants kui kommunikatsiooniprotsess sõnumi saatja (tantsu esitaja) või sõnumi vastuvõtja kaudu (Nahachewsky 1995: 13), peab arvestama asjaoluga, et praktilises kasutuses teisenevad mõistete definitsioonid pidevalt. ${ }^{12}$ Näiteks rahvamuusika mõiste on kujunenud haritlaste seas, mõjutatuna minevikku suunatud rahvusromantilisest ideoloogiast, tõstes esile antud ajahetkel oluliseks peetava rühma pärimust ja identiteeti (Särg 2002: 37). Kunstilisloominguline harrastustegevus ${ }^{13}$ on kultuuriloome oluline osa, mis peegeldab ühiskonna sotsiaal-kultuurilises kontekstis toimuvaid muutusi ning mõjutab märkimisväärse mehhanismina sotsiaalset käitumist (vt Kuutma 1998). Seda kajastab ka pagulaseestlaste rahvusliku harrastustegevuse mitmekihiline funktsioon. Meelelahutuse, esteetilise naudingu ja subjektiivse heaolu kõrval peetakse rahvatantsu oluliseks järjepidevuse säilitamise ja identiteedi teguriks (Nemeržitski \& Zajedova 2015: 69).

Mõistet (eesti) rahvatants kasutati uurimuses kõige laiemas tähenduses, millesse hõlmati sõna otseses mõttes rahva tants nii minevikus kui ka tänapäeval, nii folkloorne kui ka autoritants ning nende vahevormid ehk töötlusastmed. Mõõtuandvaks kujunes aga integreeritud käsitlus, mis ühendab tervikuks teoreetilise ja ajaloolise lähenemise ning sotsiaal-kultuurilised kontekstid (Youngerman 1977, viidatud Giurchescu \& Torp 1991: 5). Tantsu seosed teiste sotsiaalsete tegevustega kinnitavad mõtet, et tants on loomulik osa teatavast elustiilist või -mudelist. Vajalikku teoreetilist toetust selleks, et integreerida kõik dimensioonid, mis määratlevad tantsu koherentse ja dünaamilise faktorina, pakub kultuuriteksti kontseptsioon (Winner 1984, viidatud Giurchescu \& Torp 1991: 5), mis võimaldab igat tantsu suursündmust analüüsida kui kompleksset ja ühtaegu väga spetsiifilist kultuuriteksti.

\section{Uurimisküsimused ja metoodika}

Projekti teemaks ning peamiseks eesmärgiks oli uurida rahvatantsijate ja suurürituste rolli omakultuuri hoidmisel erinevatel eestlaste korraldatud suurpidudel ning leida arvestatavat teavet rahvatantsu suursündmuste seoste 
kohta nii kodu- kui ka väliseestlaste seas. Võttes arvesse varasemaid teoreetilisi käsitlusi, eesti rahvatantsu ajaloolist traditsiooni ning asjakohasust eestlaste suurürituste uurimise kontekstis, ${ }^{14}$ oli eesmärgiks uurida, mis motiveerib tänapäeval rahvatantsuga tegelema ja suurpidudel osalema ning missugune on nende osalemise eelistus ja motiivid. Andmeid koguti rahvatantsuharrastajate motiveerituse kohta nii kodu- kui ka väliseesti kogukondades. Välitöid tehti põhiliselt Eestis ja väljaspool Eestit toimuvate väliseestlaste suurpidude eel, peo ajal ning järel. Andmeid koguti Soome-Eesti III tantsupeol (2012), Austraalia eesti päevadel XXIV Sydneys (2012), Estivalil (2013), Seedrioru Suviharja laulupeol, LEP-ESTO (Lääneranniku eesti päevade ja ESTO ühisel suurpeol 2013), XXVI laulu-ja XIX tantsupeol (2014). ${ }^{15}$ Küsimustele vastamisel kombineeriti nii kvantitatiiv- kui kvalitatiivuuringuid, kusjuures kvantitatiivne, kirjaliku testina läbiviidud uurimus keskendus rahvatantsuharrastuse ja rahvatantsupidudel osalemise motiividele. ${ }^{16} \mathrm{Kodu}$ - ja väliseestlaste rahvatantsu harrastamise motiveerituse võrdlemiseks viidi läbi sõltumatute valimitega t-test.

Kvalitatiivne poolstruktureeritud intervjuudega osa oli suunatud rahvatantsuharrastusele, selle olulisusele rahvuskultuuri säilitamisel ning suurpidudel

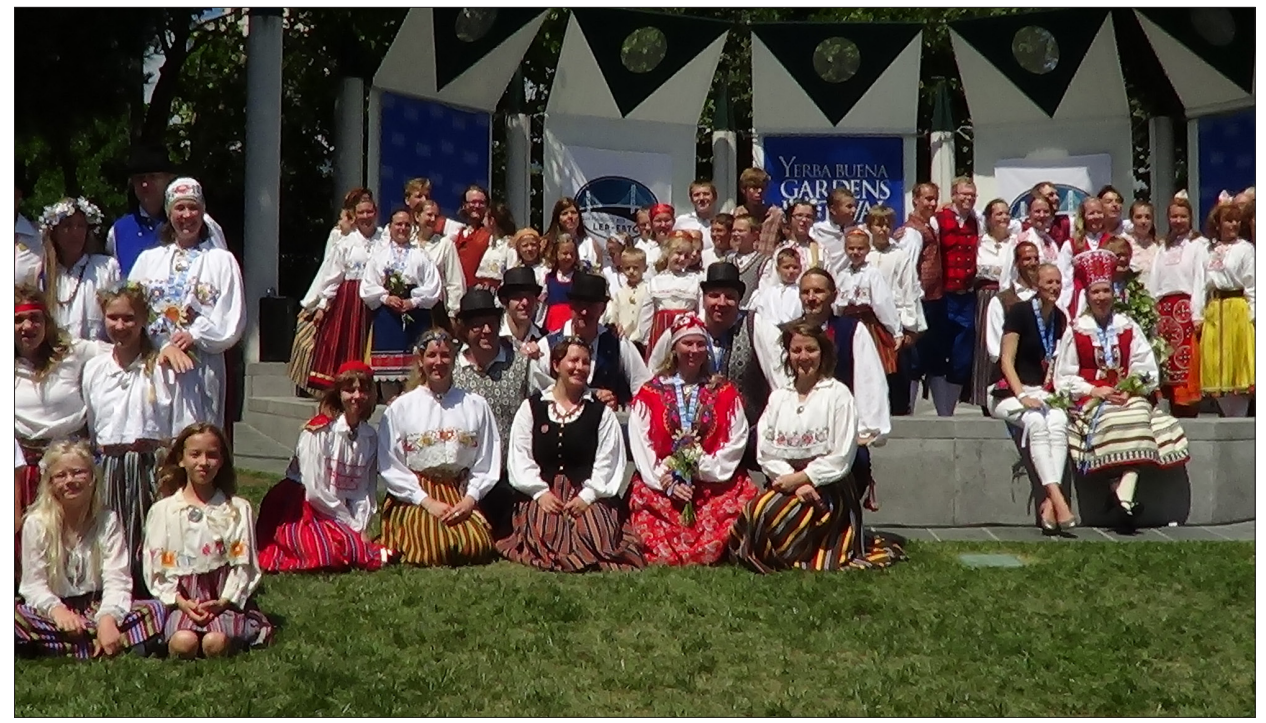

Rahvatantsupeo lõpetamine San Francisco imelises linnapargis Yerba Buena Gardensis. Pildil on igas eas väliseesti rahvatantsijad Ameerika mandrilt (ida- ja läänerannikult ning Kanadast). Iivi Zajedova foto 2013. 


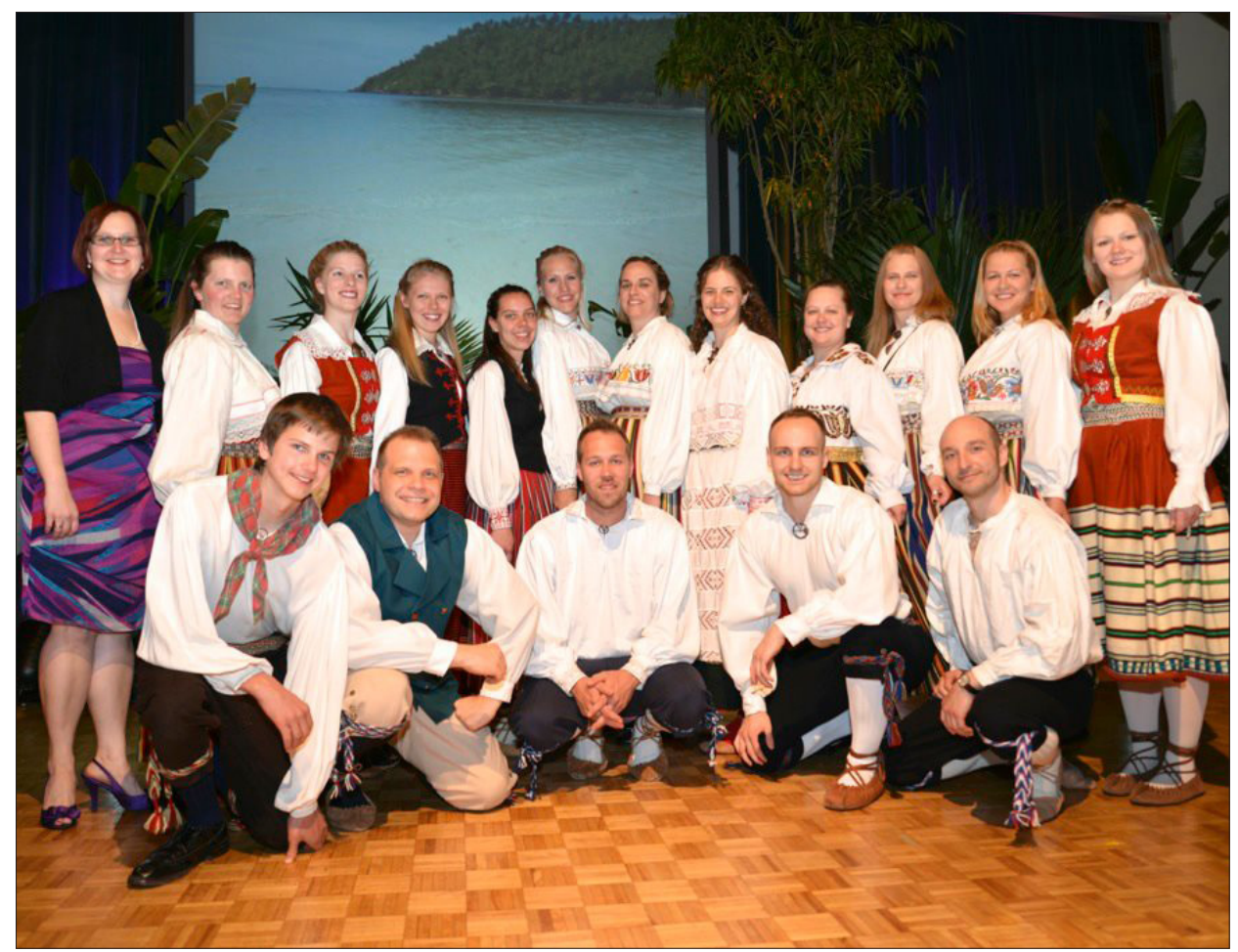

Rahvatantsurühma Kungla tantsijad Torontost. Iivi Zajedova foto 2012.

osalemise põhjustele. Kvalitatiivse uuringuosa eesmärk oli täiendada kvantitatiivses etapis saadud tulemusi, illustreerimaks ning avamaks nende sisu ja tähendust rahvatantsuharrastajate silmis. Kriteeriumiks intervjuu respondentide valikul oli vähemalt kolmeaastane rahvatantsuga tegelemise kogemus, mis andis võimaluse saada andmeid tantsijate arvamuste ja tunnete kohta.

\section{Tulemused}

Materjali analüüsi tulemusel saadi viis rahvatantsuharrastajale olulist põhikategooriat:

Motivatsioon: kaaslastega koos olemine, soov näidata oma tantsuoskust, esinemise põnevus, hea füüsilise vormi säilitamine, meeldib tantsida, vabatahtliku kaasamise aspekt (eriti noorte puhul - tuttavaks saamine toimub vabatahtlikult ja meeldival moel). 
Identiteet: näitamaks oma ajaloolisi juuri ning päritolu (sageli väliseestlastel väga oluline), et ollakse osa eesti kultuurist.

Isiklikud suhted: sotsialiseerumisvahend, uute sõprade leidmine ja vanade hoidmine. Eriti väliseestlaste puhul on rahvatantsul haruldane omadus tuua selle tegevuse juurde terve perekond. Pole harvad needki juhud, mil mitteeestlasest abikaasa tuli samuti rahvatantsu trenni või üritusele. Isiklikud suhted peegelduvad ka pealtvaatajates, sh publiku äratundmine, silmside ja suhestumine pealtvaatajatega.

Seos teiste tegevustega: üks rahvatantsule ainuomastest aspektidest (eriti väliseestlaste silmis) on see, et võimaldab ka nendel, kes enam ei valda eesti keelt, tunda end eesti kultuuri osana.

Eriline tähendus: ajaloolised kultuurisidemed oma kodumaaga. Midagi, mida tuleb hoida ning pärandada oma lastele. Rahvatantsu harrastamine on ühenduslüli erinevate väljendusvormide vahel (rahvariided, muusika jms) andes sellega erilisuse tunde.

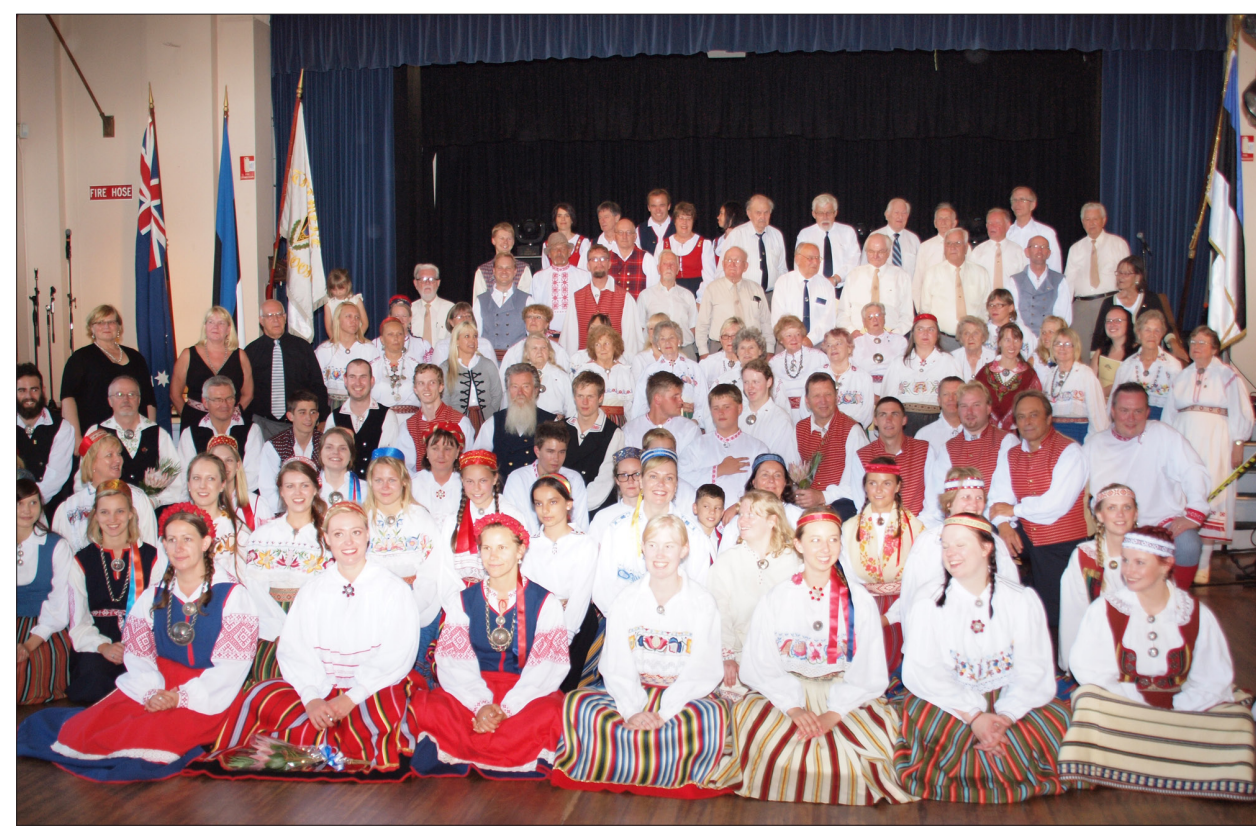

Austraalia Eesti Päevad. Esiridades rahvatantsijad Adelaide'ist, Melbourne’ist ja Sydneyst, tagaridades samade linnade laulukoorid. Iivi Zajedova foto 2012. 
Rahvatantsu tegelemise ning rahvatantsuüritustele minemise põhjused viitasid sellele, et rahvatants on oluline subjektiivse heaolu ning elukvaliteedi parandamise seisukohalt. Pidudele mindi ka uusi sõpru leidma ja olemasolevate tuttavatega suhtlema.

Tulemused näitasid ka kodueestlaste ja väliseestlaste erinevusi: kodueestlased rõhutasid mitmeid motiveerivaid faktoreid enam kui väliseestlased, sealhulgas näiteks soovi olla heas füüsilises vormis, esineda publikule ja kogeda positiivseid emotsioone. Tulemustest võis järeldada, et kodueestlastele on olulisemad eeskätt rahvatantsu harrastuslikud aspektid, samas väliseestlastele on olulisem tunda ennast oma esivanemate kultuuri ja rahvuse esindajana, mis toetab rahvakultuuri edasikandumist ning rahvusliku identiteedi säilimist (Nemeržitski \& Zajedova 2015: 62).

Pidude mastaabi eelistuses olid kodueestlaste silmis olulisemad riigisisesed suurüritused, väliseestlastele aga kohalikud või piirkondlikud üritused.

\section{Kokkuvõtteks}

Rahvatantsuharrastajate valikute, suurpidudel osalemise motiivide analüüsimisel aastail 2012-2015, ilmnes kodu- ja väliseesti rahvatantsijate vahel sarnasusi ja ka erinevusi. Saadud teave võiks luua eelduse nende edaspidiseks lähendamiseks, ühendades sama valdkonna inimesi. Uuringud on leidnud kinnituse, et väliseesti kultuurielu ja ühistegevus on endiselt elujõuline.

Uuringu, konverentsi ja ajakirjanumbri üks ja sugugi mitte vähem tähtis eesmärk oli ja on tekitada huvi Eesti suurpidude kui identiteeti loova ja kinnitava rituaali tuleviku vastu ning arutelu, kuidas edendada ühist kultuurivälja kodueesti ja väliseesti kogukondade vahel. ${ }^{17}$ Kusjuures keskseks teemaks on väliseestlaste panus omakultuuri edasikandmisel ning korrapäraselt toimuvad suurpeod. Kahjuks peab nentima, et Eesti meedia ei kajasta praeguseni piisavalt pagulaseestlaste ja nende järglaste elukäiku ja tegevust ega ka tänaseni korrapäraselt toimivaid suurpidusid. Samas väliseesti meedia kajastab Eestis toimuvat. Tekibki küsimus, kuivõrd on väljaspool Eestit korraldatud eestlaste suurpeod eesti rahva kultuuri loomulik osa? Kui see seda ei ole, siis millest jääb Eesti omakultuur ilma? Ja millest jäävad ilma väliseesti kogukonnad? Üheshingamist ega tasakaalu üksteise tegemistest osasaamisel kahe vägivaldselt lahutatud kogukonna vahel pole igatahes piisavalt veel tekkinud. 


\section{Tänuavaldus}

Lõpetuseks tahaksin tänada artiklite autoreid ja ajakirja toimetuse liikmeid, kes kõik on omal moel siinset teemanumbrit kujundanud.

\section{Kommentaarid}

1 Käesoleva teemanumbri sissejuhatus on seotud ETF grandiga 9132 "Rahvatantsuharrastuse ja rahvatantsijate suurürituste roll omakultuuri hoidmisel".

${ }^{2}$ Vthttp://www.tlu.ee/et/Loodus-ja-terviseteaduste-instituut/Teadus/konverentsid/Eestikultuuri-suurpeod-maailmaparandis (10.03.2016).

${ }^{3}$ Stanislav Nemeržitski ja Iivi Zajedova ettekande põhjal kirjutatud artikkel ilmus Mäetaguste 62. numbris (2015b).

4 Vt lisaks Šmidchens 2014.

${ }^{5}$ Salvestatud videointervjuud asuvad praegu uuringus osalejate valduses, neile otsitakse sobivat hoiukohta. Väljaspool Eestit ilmunud väliseesti seltside ja ühenduste väljaannetest kasutati nt ka: Stockholmis väljaantud Eesti kroonika 1957; Eesti Rootsis (1976); Adelaide’i Eesti Folkloori Rühma albumit Eesti rahvatants Adelaide’is, LõunaAustraalias 1948-1993; Austraalia Eesti Seltside Liidu Eestlased Austraalias I (1988) ning Eestlased Austraalias II ja Uus-Meremaal (1993); ajaloolist koguteost Eestlased Kanadas II (1985); Kanadas välja antud ESTO 84; Lääneranniku eesti päevad 1953-1999; Seedrioru, 1955-1980 (koguteos eestlaste tegevusest Kanadas).

6 Saar Poll OÜ kultuuritarbimise uuringu 2003. aasta aruanne (http://www.saarpoll. ee/UserFiles/File/kultuuritarbimise_uuring_2003.pdf, vt ka tabelit lk 10); Marju Lauristini ja Peeter Vihalemma poolt 2013. aastal läbiviidud sotsioloogiline uuring kinnitas, et "tantsupidudel on osalenud 10\%, publiku hulgas olnud 36\% ja ülekandeid jälginud 77\% rahvast" (vrd ka Vissel 2004).

7 Vt lähemalt: http://sa.laulupidu.ee/unesco/2009 (05.04.2016).

8 Vt http://www.rahvakultuur.ee/s2/1652_10540_613_Loe_edasi.pdf.

9 Vt ka Eesti Rahvatantsu ja Rahvamuusika seltsi kodulehel uudist "Täna, 100 aastat tagasi, esitati eesti rahvatantse esimest korda laval!" (http://www.errs.ee/ - 31.03.2016).

10 Tookord kuulus ÜENÜ ridadesse juba üle Eesti 176 rahvatantsu harrastusrühma kokku 3000 tantsijaga. Ja kuigi tantsupeod algasid 1930. aastail spordipidustuste osana, sai rahvatants nende tooniandvaks osaks (vt Arraste jt 2009: 9).

${ }^{11}$ Sille Kapperi dissertatsiooni uurimuslikus osas jälgitakse 21. sajandi rahvatantsu üldmõiste väljakujunenud tähenduste paljusust (kättesaadav TLÜ Akadeemilise Raamatukogu repositooriumis E-Ait http://e-ait.tlulib.ee/341/).

${ }^{12}$ Otstarbekaks peeti tegeleda uuringu käigus süstemaatiliselt tantsuvaldkonna mõistete defineerimise ja piiritlemisega (analoogselt muusikauuringutega). Rahvatantsu mõiste muutumine ajas ja seosed erinevate diskursustega nagu folkloor, rahvus, harrastustegevus ning seotus tervise- ja suhtlemisprobleemidega on eriti laialivalguv ja seega ka problemaatiline ülesanne (Kapper 2012; Kapper 2013b; Kapper 2015; Rüütel 
\& Kapper 2015). Grandi põhitäitja Sille Kapper jälgis oma doktoritöö uurimuslikus osas üldmõiste rahvatants 21. sajandi alguseks väljakujunenud tähenduste paljusust (Kapper 2013a).

${ }^{13}$ Harrastustegevuse diskursuses on rahvatants kui vaba aja tegevus, mis seostub nii pärimus- kui ka rahvuslike tantsude õppimises esitamiseks või meelelahutuse, suhtlemise vm eesmärgil (vt ka Kapper 2012: 7-27).

14 2011. aastal Ülemaailmse Eesti Kesknõukogu täiskogu aastakoosolekul Lundis ütles oma ettekandes Austraalia seltside esindaja Iivo Tuul, et just rahvatantsust võiks saada eestluse hoidja, sest erinevates riikides on palju eesti juurtega ja eestlusesse positiivselt suhtuvaid inimesi, kes enam ei valda eesti keelt, kuid seda ressurssi ei tohiks lasta niisama kaduda.

${ }^{15}$ Soome-Eesti III tantsupidu, Austraalia Eesti Päevad (vt http://www.ep2012sydney. org.au/index.php), Estival (http://www.estival.se/), Seedrioru Suviharja, LEP-ESTO (http://lep-esto2013.com/), XXVI laulu- ja XIX tantsupidu.

${ }^{16}$ Uuringu valimis oli 387 küsitletut ja 12 intervjuud. Statistilise andmetöötluse meetoditena kasutati kahesuunalisi sagedustabeleid ja korrelatsioonianalüüsi t-testi ja regressioonianalüüsi, uuriti seoseid subjektiivse heaolu ja rahvatantsu-harrastusega tegelemise vahel (vt Nemeržitski \& Zajedova 2015).

${ }^{17}$ Professor Martin Ehala arutles 14. septembril 2015 TLÜ konverentsil ja 16. septembril toimunud rahvuskaaslaste konverentsil Narvas selle üle, kuidas määratleda, luua ja hoida ühiseid väärtusi küsides, kas see on eesti avalikkuse huvides.

\section{Kirjandus}

Aassalu, Heino 1999. Murrangud Eesti rahvatantsus ja harrastusrahvatantsus. Tallinn: Rahvakultuuri Arendus- ja Koolituskeskus.

Arraste, Angela 2009. Tantsupeod eestlaste kultuuriloos. Magistritöö. Tallinn: Tallinna Ülikooli Kunstide Instituut, koreograafia osakond.

Arraste, Angela \& Zajedova, Iivi \& Rüütel, Eha 2011. Rahvatantsuharrastusega seotud kultuuri-ja suurpeod väljaspool Eestit. Mäetagused 49, 49-64 (doi:10.7592/ MT2011.49. valispeod).

Arraste jt 2009 = Arraste, Lille-Astra \& Adamson, Ilma \& Ammas, Anneli \& Feršel, Ülle \& Tiis, Kadri \& Žigurs, Juris \& Valner, Kadri (koost) 2009. 75 aastat eesti tantsupidusid. Tallinn: Varrak.

Aun, Karl \& Pärkma, Harri \& Tammemägi, Voldemar (toim) 1980. Seedrioru, 1955-1980. Toronto: Lõuna-Ontario Eestlaste Suvekodu.

Cohen-Stratyner, Barbara 2001. Social Dance: Contexts and Definitions. Dance Research Journal 33 (2). Social and Popular Dance (Winter). Urbani University of Illinois Press, lk 121-124.

Danesi, Marcel \& Perron, Paul 2005. Kultuuride analü̈̈s. Tallinn: Valgus, 31. 
Eesti kroonika 1957 = Kokla, Juhan \& Raukas, Helga \& Sepp, Reino \& Üürike, Madis (toim) 1956. Eesti kroonika 1957. Esimene aastakäik. Stockholm: EMP.

Eestlased Austraalias I = Haas, Õie \& Siska, Voldemar (toim) 1988. Eestlased Austraalias I. Adelaide: Austraalia Seltside Liit.

Eestlased Austraalias II = Neeme, Gunnar \& Freymuth, Lydia \& Metsar, Aime \& Ole, Asta (toim) 1993. Eestlased Austraalias II ja Uus-Meremaal. Melbourne: Austraalia Eesti Seltside Liit.

Eestlased Kanadas II = Lillakas, Valdu \& Kopvillem, Peeter \& Kuris, Eino \& Kurlents, Alfred \& Puust, Lilian \& Runge, Ene \& Soomet, Ermi \& Vaikla, Karl (toim) 1985. Eestlased Kanadas: ajalooline koguteos II. Toronto: Kanada eestlaste ajaloo komisjon.

ESTO 84 = Holmberg, Livia (toim) 1985. ESTO 84 väljaanne. Canada: Thorn Press Ltd., lk 150-152.

Giurchescu, Anca \& Torp, Lisbet 1991. Theory and Methods in Dance Research: A European approach to the holistic study of dance. Christensen, Dieter (peatoim). Yearbook for Traditional Music 23: 1 (doi: 10.2307/768392).

Hofstede, Geert 2001. Culture's Consequences: Comparing Values, Behaviors, Institutions and Organizations Across Nations. Second Edition. California: Sage Publications.

Hoppu, Petri 2004. Tantsufolklorism tänapäeva Soomes. Rüütel, Ingrid (koost). Pärimusmuusika muutuvas ühiskonnas 2 . Töid etnomusikoloogia alalt 2. Tallinn: Eesti Kirjandusmuuseumi etnomusikoloogia osakond \& Eesti Rahvuslik Folkloorinõukogu, lk 97-101.

Idla, Ingrid \& Normet, Dagmar \& Tiik, Aksel 1991. Ernst Idla - võlur Tallinnast. Tallinn: Eesti Raamat.

Jürgenson Aivar 2012. Disaporaa eestlaste maastikest. Mäetagused 50, lk 7-28 (doi:10.7592/MT2012.50.jyrgenson).

Kalmann, Helmuth (koost) 2000. Lääneranniku eesti päevad 1953-1999. Piltlik ülevaade Lääneranniku Eesti päevade tekkimisest ja arengust möödunud 46 aasta jooksul koos andmetega osavõtust, tegevusest ja juhtkonnast. Portland (Oregon).

Kangro, Bernard 1976. Eesti Rootsis. Ülevaade sõnas ja pildis. Lund: Eesti Kirjanike Kooperatiiv.

Kangur, Valdek 1993. Eesti rahvatants Adelaide’is, Lõuna Austraalias 1948-1993. Adelaide: Eesti Folkloori Rühm Vikerkaar.

Kapper, Sille 2012. Rahvatantsu mõistest eesti kultuuriruumis. Lock, Gerhard \& Zajedova, Iivi (koost). Kunstide vastastoimed: Keha, tants ja muusika. Res Artis 1. Tallinn: TLÜ, lk 7-27.

Kapper, Sille 2013a. Muutuv pärimustants: kontseptsioonid ja realisatsioonid Eestis 2008-2013. Tallinna Ülikool, Humanitaarteaduste dissertatsioonid 35. Tallinn: Tallinna Ülikooli Kirjastus. 
Kapper, Sille 2013b. Estonian Folk Dance: Terms and Concepts in Theory and Practice. Folklore: Electronic Journal of Folklore 54, lk 73-96 (doi: 10.7592/FEJF2013.54.kapper).

Kapper, Sille 2015. Loomulikkuse küsimus. Mäetagused 59, lk 27-50 (doi:10.7592/ MT2015.59.kapper).

Kermik, Heino (koost) 1983. Ullo Toomi: Kaerajaanist tantsupeoni. Koostanud ja Ullo Toomi elu- ning eesti rahvatantsulooks täiendanud Heino Kermik. Tallinn: Eesti Raamat.

Kool, Ferdinand 1999. DP Kroonika: Eesti pagulased Saksamaal 1944-1951. Lakewood, NJ: Eesti Arhiiv Ühendriikides.

Kuutma, Kristin 1998. Kultuuriidentiteet, rahvuslus ja muutused laulutraditsioonis. Mäetagused 7, lk (doi: 10.7592/MT1998.07.kuutma).

Lauristin, Marju \& Vihalemm, Peeter 2013. Minu laulu- ja tantsupidu: sotsioloogilise uuringu aruanne. Tallinn: Eesti Laulu- ja Tantsupeo SA (http://sa.laulupidu.ee/wpcontent/uploads/2015/01/Laulupeo-uuringu-aruanne-25-aprill-PARANDUSTEGAKODULEHELE.pdf - 1. aprill 2016).

Nahachewsky, Andriy 1995. Participatory and Presentational Dance as Ethnochoreological Categories. Dance Research Journal 27 (1), Spring. Urbana: University of Illinois Press, lk 1-15 (doi: 10.2307/1478426).

Nemeržitski, Stanislav \& Zajedova, Iivi 2015. Rahvatantsu harrastamine ja suurpidudest osavõtmine: põhjused ja seosed subjektiivse heaoluga. Mäetagused 62, lk 55-74 (doi:10.7592/MT2015.62.rahvatants).

Raudkats, Anna 1926. Eesti rahvatantsud. Tartu: Postimehe trükk [kordustrükk 2001].

Rüütel, Ingrid \& Kapper, Sille 2015. Kihnu tantsud. Tartu: Eesti Kirjandusmuuseumi Teaduskirjastus.

Saar Poll 2003 = Kultuuri-tarbimise uuring. Elanikkonna küsitlus. Kevad 2003. Saar Poll OÜ (http://www.saarpoll.ee/UserFiles/File/kultuuritarbimise_uuring_2003.pdf 1. aprill 2016).

Särg, Taive 2002. Rahvamuusika mõiste kujunemisest - "rahva”teaduste ja musikoloogia vahel. Ojamaa, Triinu \& Rüütel, Ingrid (koost, toim). Pärimusmuusika muutuvas ühiskonnas 1. Töid etnomusikoloogia alalt 1. Tallinn: Eesti Kirjandusmuuseumi etnomusikoloogia osakond, lk 9-44.

Šmidchens, Guntis 2014. The Power of Song. Nonviolent National Culture in the Baltic Singing Revolution. USA: The Universty of Washington Press.

Zajedova jt 2009 = Zajedova, Iivi \& Rüütel, Eha \& Arraste, Angela \& Järvela, Kalev 2009. Rahvatantsuharrastus pagulaseestlaste hulgas ning selle roll eestluse säilimisel. Mäetagused 41, lk 99-122 (doi: 10.7592/MT2009.41.pagulus).

Zajedova, Iivi 2013a. Eesti päevad Austraalias. Mäetagused 53, lk 136-137 (http://www. folklore.ee/tagused/nr53/u04.pdf - 1. aprill 2016).

Zajedova, Iivi 2013b. Väliseestlaste kahekordne suurpidu San Franciscos. Mäetagused 55, lk 111-113 (http://www.folklore.ee/tagused/nr55/u01.pdf - 1. aprill 2016). 
Zajedova, Iivi 2015. Eestlaste kultuuripidu “Üle ilma”. Mäetagused 59, lk 166-168 (http:// www.folklore.ee/tagused/nr59/u04.pdf - 1. aprill 2016).

Talve, Ilmar 2004. Eesti kultuurilugu. Keskaja algusest Eesti iseseisvuseni. Tartu: Ilmamaa.

Tõnnus, Richard 1991. Anna Raudkats oma ajas. Tallinn: Eesti Raamat.

Vasilas, Vasilios 2014. Across Lands and Ocens... to Freedom: Stories and Photographs from the Estonian Journey to Australia \& New Zealand 2. Riverwood: Vasilios Vasilas.

ÕS = Leemets, Tiina \& Mäearu, Sirje \& Raadik, Maire \& Erelt, Tiiu (koost) 1999. Eesti keele sõnaraamat: ÕS 1999. Tallinn: Eesti keele Sihtasutus (http://www.eki.ee/dict/qs/ index.cgi? $\mathrm{Q}=$ traditsioon $\& \mathrm{~F}=\mathrm{M}-5$. aprill 2016).

Vissel, Anu 2004. Rahvatantsu asendist eestlaste kultuuripildis ja harrastustes. Rüütel, Ingrid (koost). Pärimusmuusika muutuvas ühiskonnas 2. Töid etnomusikoloogia alalt 2. Tallinn: Eesti Kirjandusmuuseumi etnomusikoloogia osakond, Eesti Rahvuslik Folkloorinõukogu, lk 109-127.

\section{Summary}

\section{National cultural festivals as part of the world's cultural heritage}

Iivi Zajedova

Keywords: festivals, folk dance, hobby activities, tradition

The tradition of Estonians' cultural festivals is a rich topic and may be considered profoundly distinctive for Estonian people. It is a unique way of maintaining and advancing the traditions of national heritage through a variety of activities. Since after World War II a forced separation took place in Estonian national culture and many citizens of the former Republic of Estonia escaped from the Soviet occupation to the Free World (thereby splitting geographically into the groups of homeland Estonians and Estonians abroad), the tradition of cultural festivals continued on both sides of the Iron Curtain, in an effort to maintain traditions under different circumstances. This special issue of the journal is the outcome of a project begun in 2012, to investigate the role of folk dance hobby activities and festival traditions in the maintenance of national culture. During the compilation of the special issue the focus shifted towards the question of the role of Estonians' traditional festivals in the ever-changing world - their viability and transmission of the traditions of national identity both in Estonia and abroad. This issue covers the experiences of hobbyists in traditional cultural activities, their involvement in festivals, and their cultural contribution, both in Estonia and in communities outside it. Among the basic themes of the articles the following deserve special attention: the place of the Baltic countries' song festivals in the world cultural heritage and 
the relationship between new and traditional songs; the role of dance festivals in the preservation and transmission of traditional dancing skills in contemporary Estonia and the nature of cultural heritage being maintained at dance festivals; the role of folk dance among the Skolt Saami, our neighbours in the North, in shaping their history, identity, and future, as well as the connections between contemporary Skolt Saami folk dance and identity; the revitalisation of old folk musical instrument traditions both in Estonia and among the Estonian diaspora; the split and repression in the realm of choir music, due to the forced separation by a foreign power; the recording of World War II refugees' cultural events on narrow gauge film in Sweden and the identification of the filmed individuals by a group of experts. Another and not less important goal of this issue is to stimulate a more wide-ranging discussion in Estonian society about the role of hobbies and traditional festivals, especially outside Estonia, which are an integral part of Estonian national culture and Estonian folk culture. 